probably resume its course in the middle of September, terminate its voyage in the harbour of Horten."

The members of the expedition are the same this year as last, viz., Profs. Dr. H. Mohn, meteorologist ; Dr. G. D. Sars, Dr. Danielssen, and Herr H. Friele, zoologists; candidate Tornœe, chemist; assistant-candidate Schmelck, physicist and chemist ; and the landscapepainter Herr Schiertz, as artist. The Voeringen will be commanded this year, as formerly, by Capt. Wille of the Royal (Norwegian) Navy, the second in command being the sailing-master, Capt. Greig. The expedition carries with it several valuable new instruments for measuring more exactly the temperature of the water at great depths; some of them have, with great good will, been obtained from the members of the English Challenger expedition. As in the preceding years, Prof. H. Mohn will send to NATURE communications from the expedition.

\section{PHYSICAL SCIENCE FOR ARTISTS ${ }^{1}$}

VI.

T $\overline{\mathrm{HE}}$ diagrams given in my last article should have made it quite clear that the various sunset and sunrise colours are due to the absorption produced by different thicknesses of aqueous vapour; that the colours of clouds are due to light falling upon them after absorption by different thicknesses of aqueous vapour; and finally that the blue colour of the sky in the zenith is due to the fact that the pure gases in our atmosphere exist in that molecular grouping which vibrates in harmony with the short waves of light.

The blue sky, however, is scarcely ever a true blue. Between us and it there is ever a misty veil which reflects to us the white light of the sun, as an examination of it" by a pocket spectroscope will prove to anybody. It is to the variation in the quantity of this misty veil that the difference in the colour in the sky at great and low elevations, in different climates, and in the same climate, when clouds are about to form and when scarcely the germs of clouds are present, is to be ascribed. The thickness of our atmosphere is so moderate that neither the hypothetical red nor the blue molecules of aqueous vapour are competent, except during thunderstorms, to influence its colour as they undoubtedly do near the horizon.

A glance at Fig. 4 in the last article will explain how it is that sometimes in the case of clouds we find the beforestated order of sunset colours reversed. If, for instance, we imagine a cloud lying along the curve $x s^{\prime}$, an observer at $o$ will see a cloud at $x$ higher above the horizon than one at $s^{\prime}$, but the cloud at $x$ will have received light through a greater thickness of atmosphere than the cloud at $s^{\prime}$. The red, therefore, at $x$ will be more foncé than at $s^{\prime}$; the order of colour, though not of brilliancy, will be reversed.

So far we have considered these colours looking towards the rising or setting sun. Let us now turn our back on that luminary. It will be at once obvious that if, for instance, we take a point on the horizon, there will be an enormous increase in the thickness of atmosphere traversed by the ray; indeed, we may say that for this point the absorption will be threefold. Hence a considerable reduction of light, a ruddier tinge, due to the increased absorption of the more complex molecules, and a mingling of the ruddier light with the blue sky.

In the voyage which I made to India in I87I I scarcely ever missed a sunrise or a sunset, and although the point of sunrise or sunset was almost always the scene of a succession of glories unsurpassed in beauty, the point opposite was, if possible, more interesting, the colours were more subdued, and of a more composite order, but

I Continued frcm p. 557 . the work of law went on there, as elsewhere. If any clouds happened to be overhead, their greatest glory, which, as I have already shown, can only be put on when the sun is below the horizon-and the sun rises or sinks much more rapidly there than with us-was the herald of the shadow of the earth on the illuminated sky, which crept on a gigantic, mysterious crescent. That the shadow of the earth could thus be seen was new to me, and I am the more glad, therefore, seeing that many may doubt it still, to substantiate my observation and its explanation by a quotation from Prof. Brücke, one of the most distinguished members of the Vienna University. Prof. Briicke has been doing on the Continent what I have been attempting to do in these articles, and just before my last one appeared I saw in La Revue Scientifique an extract from his forthcoming work "Principes Scientifiques des Beaux Arts." I am delighted to see how much at one we are, but for the moment I shall content myself by giving what he says on the point to which I have referred. Talking of sunset he writes:-

"We see on the horizon to the east a grey blue stratum rising higher and higher, and stopping at that portion of the sky coloured red : it is the shadow of the earth.

"The shadow of the earth must always encounter an unilluminated part of the atmosphere. As this shadow does not fall on a surface, but on a great number of particles spread abroad in space, it is material, that is to say, it has three dimensions, and we see it, foreshortened -in perspective.

"Sometimes the regions above it are divided in a radial direction into sectors, some of which are dark, like the shadow of the earth, others red. These resemble in the sky the rays of the aurora borealis, and often change their place and size; in French they are tcrmed 'les rayons de crépuscule.' They are due to the fact that in the path of the solar rays there are masses of clouds which only give passage to isolated ones here and there, which make their presence felt by the luminous train which they leave among the particles of the atmosphere. Hence arise those red prismatic masses spread abroad in the air east and west. At the zenith we do not remark them, because the vision cuts across them, and the stratum of illuminated particles is not thick enough to render them sensible; but we see them painted on the eastern sky because we regard them obliquely in the sense of their length; we see them in perspective. By their nature and their mode of origin they do not differ from the beams which the setting sun throws between the intervals in the clouds, nor from those which it sometimes casts in the morning or afternoon through the clouds, when the peasants say that 'the: sun is drawing water.' "Voila un bouillon qui chauffe.' "'

This paragraph not only supports my view, but it opens up several very interesting points on which, if space permitted, there would be much to say; one or two words, however, must suffice.

The rifts to which Prof. Brücke has drawn attention do not always arise from clouds; in fact, they are not seen in their greatest vividness when they do. One evening I saw them thrown, in a perfectly cloudless sky (in fact, there had been no cloud all day), by the sky-line of Socotra, which island we had passed during the day, and which was below the horizon at the time. Capt. Parish, in command of the Mirzapore, to whom I appealed at the time, took the bearing of these rifts, which, in their sharpness and magnitude, were almost appalling, and put the question beyond all doubt.

With regard to the "sun drawing water," artists should note the absence of all colour and the radial direction of the beams, all meeting in the sun's place. For some reason or other many artists are not yet quite clear about this appearance, and compromise matters by making the beams look like a distant rain-shower. There are some notable examples of this in the South 
Kensington Museum. That phenomena so diverse in their origin and appearance should be mistaken for each other does not say too much in favour of the cultivation of the observational faculties of artists as a rule.

I shall next refer to two or three other questions which have been dealt with by Prof. Brücke in the article to which I have referred. Prof. Brücke is again with me to a certain extent in tracing the origin of most skycolour to a defect of the blue light, but he does not make the attempt to run it to earth that I have done, by ascribing it to aqueous vapour ; indeed he considers it rather due, I take it, to the presence of solid particles in the air. Thus, after pointing out that the dawn is generally orange, and the sunset redder, he states that at night the quantity of molecules capable of troubling the air is generally greater. For my own part, I should be inclined to ask whether, during the night, the molecules of aqueous vapour which absorb the blue have not been driven into higher forms--dew being one of them-owing to the reduction of temperature. This would at once explain not only the generic difference between sunrise and sunset colours, which is more marked here than in the tropics; but also the golden instead of red sunsets which accompany the formation of cloud.

Another point of difference. Prof. Brücke considers green sky as an effect of contrast produced by the quantity of red light which enters the eye. I cannot agree to this, first, because I bave given a physical reason for the green; and secondly, because I have observed it without any strong contrast of colour to mislead the eye. The considerable darkening of the green after sunset is, I believe, purely physiological; and it is an effect of so curious a nature, that it raises several interesting questions with regard to the manner in which the eye grapples with the middle colours of the spectrum, namely, the orange, yellow, and green, which can be made to change to a certain extent according as the light is more or less intense, which does not happen with the other colours.

The changes in mountain scenery form the subject of several interesting remarks by Prof. Briicke. As long as distant mountains are illuminated by a high sun, their outlines are not very clear; because, as he well puts it, the reflection of this light from the lower strata of the atmosphere is then so great that the illumination at the horizon, where mountains are, is as strong as where they are not. He then points out that at night the setting sun fills the s'zy towards the west with a great brightness which renders the profiles of the mountains between us and the sun much darker. Their contours are neatly detached, but it is not only on the horizon that this is seen; the various chains are better distinguished, and appear one behind the other like the scenes in a theatre, because the light in which we see them does not come from them but from the interposed air. The sides of the mountains which we see are dark because the other sides are turned towards the sun, but the various thicknesses of air interposed between us and them reflect to us the sunlight; hence the atmosphere of a picture is truly the work of the air.

Here is what Prof. Briicke says about sunset tints ; I do not follow him in all his explanations:- "When the sun reaches the horizon and the red tint is developed, the colours of the landscape change in their turn and the mountains themselves appear red when we regard no longer their. shadows but the illuminated air which lies in front of them." It appears to me this gives too much work to the air; a rock surface is generally as capable of dispersing red light which falls upon it, as a molecule of aqueous vapour is; "still the tint has not the intensity of the alpine colour; it is a red less intense and more empurpled, which sometimes approaches even the violet or the lilac."

I shall have a word to say on this, but I will first give Prof. Brücke's explanation :-
"Two causes are at work in this latter case; the first is the mixture of red and blue light. At night when the sky is clear the shadows are coloured a strong blue. The shadow region is illuminated by the blue light of the sky, and appears more pronounced, owing to the contrast of the reddish-yellow light, as we have already seen. The illuminated air reflects the blue rays more abundantly than the red ones, and consequently the former have the ascendency. If not scientifically correct, it is at least practically so, to suppose the blue light in which we see the mountains bathed after sunset to be mixed with purple or lilac. The second cause of the violet tone in the distances to the west is to be found in the frequent contrast. : In the west, in fact, a great part of the sky is illuminated by yellow light; often this yellow is a perfect sulphurcolour, which contrast makes objects even in the middle distance, which turn their dark sides to us, appear violet; thus, looking to the west, dark, unploughed earth appears violet when the majority of terrestrial objects turn their dark sides towards us."

An observation I made at Cannes last year leads me to think that the whole cause of this purple colour has not been stated in the foregoing. It was near the hour of sunset, and I was looking towards the southwest, delighting in the blue colour at the foot of Les Estrelles-while their crests were being gilded by the sunset-when, almost instantaneously, the valley to the north of these hills was enfiladed by a beam from the sun itself, which threw part of the aqueous vapour in the valley into a frenzy of gold. This gradually got ruddier as the sun got lower, and the amount of vapour lighted up between me and the blue vapour at the foot of the hills was at the same time reduced; the blue and the red then melted together into the richest and most beautiful purple that I, at all events, have ever seen.

We have only, then, to assume that, when we thus see purple, that colour is produced by a mixture of particles, some of which are reflecting to us the blue light of the sky, because they can do no other, while others, again, are reflecting to us the red light of sunset, because it is more powerful than the light from the sky.

J. NORMAN LOCKYER

\section{AN ECLIPSE SPECTROSCOPE}

SOME little time ago I communicated to the Royal Socicty a suggestion for the use of Mr. Rutherfurd's reflection gratings in obtaining photographs of the coming eclipse. The plan suggested was that the grating should be placed short of the focal point of a telescope, and at right angles to its axis, and that the diffracted images of the chromosphere should be received on photographic plates adjusted for the different orders of spectra on either side the axis. I am glad to learn from Prof. Newcomb that the value of this method of observation will probably be tested by Prof. Young, who is in charge of one of the six expeditions already organised to observe the eclipse. The chief defect in this mode of observation lies in the difficulty of determining the position of the lines photographed, supposing the chromospheric spectrum to vary considerably from the ordinary solar one so far as the intensity of the lines is concerned; and as it seemed desirable that these gratings should be utilised for less serious attacks, I have recently been endeavouring to see if the method can be improved.

The annexed woodcut shows one form of the new arrangement, which has many conveniences. It is a rough model on wood, but will suffice to show the method of use.

The grating, which is free to rotate, is placed in front of a little telescope of low magnifying power and the stand which carries both is so placed and the grating so 